\title{
Valores energéticos de alguns alimentos utilizados em rações para codornas japonesas ${ }^{1}$
}

\author{
Fábio Augusto Gomes ${ }^{2}$, Édison José Fassani ${ }^{3}$, Paulo Borges Rodrigues ${ }^{4}$, José Cleto da Silva Filho 5 \\ ${ }^{1}$ Parte da dissertação do primeiro autor. \\ 2 Mestrando da Faculdade de Zootecnia - UNIFENAS, Alfenas - MG, CEP: 37130-000. Bolsista CAPES. \\ 3 FZ/UNIFENAS, Alfenas - MG. \\ 4 DZO/UFLA, Lavras - MG. \\ ${ }^{5}$ DZO/UFLA, Lavras - MG.
}

RESUMO - O experimento foi conduzido para determinar os valores energéticos de 12 alimentos para codornas japonesas. Utilizaram-se 280 codornas com 19 semanas de idade, submetidas ao método de coleta total de excretas, em delineamento em blocos casualizados, com dez codornas por unidade experimental. O período experimental teve 32 dias de duração, dividido em quatro ensaios de oito dias, nos quais foram estudados dois grupos de alimentos (protéicos e energéticos), com cinco repetições cada um. Os grupos constaram de alimentos protéicos de origem animal (farinha de carne e ossos, farinha de peixe e farinha de penas e vísceras) e vegetal (farelos de soja 1 e 2) e alimentos energéticos de origem vegetal (milheto, sorgo e farelo de arroz integral) e óleo e gorduras (óleo de soja refinado, gordura de aves, sebo bovino e gordura de suínos). Os alimentos substituíram a ração-referência, à base de milho e farelo de soja, em 20\% (protéicos de origem animal), 30\% (protéicos de origem vegetal), $40 \%$ (energéticos de origem vegetal) e $10 \%$ (óleo e gorduras) na matéria natural (MN). Foram avaliados os valores de energia metabolizável aparente (EMA) e verdadeira (EMV) corrigidos pelo balanço de nitrogênio (EMAn e EMVn), e os coeficientes de metabolização da energia bruta (CMEB). As fontes protéicas estudadas, à exceção da farinha de penas e vísceras, apresentaram valores de EMAn superiores aos encontrados nas tabelas brasileiras para aves e suínos; a farinha de carne e ossos apresentou o maior CMEB $(74,06 \%)$ e a de penas e vísceras, o menor $(56,24 \%)$. Os alimentos energéticos avaliados, à exceção do sorgo, apresentaram valores de EMAnsuperiores aos referenciados nas tabelas brasileiras; o óleo de soja refinado e a gordura de suínos tiveram os maiores CMEB (95,81 e 93,32\%, respectivamente), enquanto o farelo de arroz integral apresentou o mais baixo CMEB $(61,13 \%)$.

Palavras-chave: alimentos energéticos, alimentos protéicos, óleo e gorduras

\section{Energy values of some feeds used in the Japanese quails diets}

\begin{abstract}
The experiment was conducted to determine the energy values of 12 feeds for Japanese quails. Two hundred and eighty quails averaging 19 weeks old were submitted to the method of total feces collection as a randomized block design, with ten quails per experimental unit. The experimental period lasted 32 days, divided into four trials of eight days each, where two groups of feeds were studied (protein and energetic), with five replicates each: protein of animal origin (meat and bone meal, fish meal and feather and viscera meal) and plant (soybean meals 1 and 2), as well as energetic feeds of plant origin (millet, sorghum and whole rice bran) and oil and fats (refined soybean oil, poultry fat, beef tallow and swine fat). The feeds replaced the reference diet (corn, soybean meal-based diet), as-fed, in 20\% (protein of animal origin), 30\% (protein of plant origin), $40 \%$ (energetic of plant origin) and 10\% (oil and fats). The values of apparent metabolizable energy (AME), true (TME), AME and TME corrected by nitrogen balance (AMEn and TMEn), as well as the metabolization coefficients of gross energy (MGEC) were the analyzed variables. The protein sources, with the exception of feather and viscera meal, had values of AMEn higher than those of the Brazilian tables for poultry and swine, meat and bone meal showed the greatest MGEC (74.06\%), while feather and viscera meal, the lowest $(56.24 \%)$. The energetic feeds, with exception of sorghum, showed higher values of AMEn than those cited by the Brazilian tables for poultry and swine, and both refined soybean oil and swine fat had the highest MGEC (95.81\% and 93.32\%, respectively), while whole rice bran, the lowest $(61.13 \%)$.
\end{abstract}

Key Words: energetic feeds, oil and fats, protein feeds

\section{Introdução}

A coturnicultura nacional destina-se principalmente à produção de ovos, firmando-se nos últimos anos como importante segmento do cenário avícola industrial. No entanto, no campo da nutrição, a formulação de rações para codornas baseia-se em valores de energia metabolizável de alimentos determinados com frangos de corte ou galinhas 
poedeiras, o que, na maioria das vezes, não permite balancear uma ração que atenda às necessidades reais da ave.

Uma vez que as codornas possuem algumas diferenças marcantes, como, por exemplo, maior velocidade no tempo de passagem dos alimentos no trato digestório, o uso de valores energéticos determinados em outras espécies de aves pode ocasionar efeitos de sub ou supernutrição, refletindo nos aspectos produtivos e econômicos. Segundo Murakami \& Furlan (2002), esta extrapolação entre as espécies é questionável, visto que o aproveitamento energético de determinado alimento está relacionado à velocidade de passagem pelo trato digestório, que, por sua vez, depende de outras variáveis, como aspecto físico, umidade e composição do alimento, quantidade ingerida, freqüência e tempo de fornecimento, além das características intrínsecas do animal.

O cuidado no conhecimento acurado do conteúdo químico e energético dos alimentos deve ser redobrado quando se faz uso principalmente de subprodutos de origem animal, haja vista a pouca padronização desses alimentos, cujos valores nutritivos variam conforme o processamento a que são submetidos e ao tipo e às proporções de seus constituintes, o que, segundo Albino \& Silva (1996), resulta da dificuldade dos setores de graxaria dos abatedouros em estabelecer um padrão contínuo nos ingredientes utilizados.

As dietas avícolas geralmente são formuladas à base de milho e farelo de soja. Nas dietas para codornas, verifica-se que, na prática, a proporção de farelo de soja é superior, em virtude das maiores exigências de proteína desta ave, que, segundo dados apresentados por Lázaro et al. (2005), oscilam entre 17 e $24 \%$ durante a fase de postura. O farelo de soja apresenta grandes vantagens de uso quando comparado a outras fontes protéicas, porém, possui grande proporção de polissacarídeos não-amiláceos (PNAs) que alteram a digestibilidade por afetar a viscosidade intestinal (Annison \& Choct, 1991).

À medida que os custos de produção aumentam, os nutricionistas verificam a necessidade de alimentos alternativos que atendam às exigências dos animais nas suas diferentes fases de produção. Assim, de acordo com Fialho \& Barbosa (1999), no caso de alimentos energéticos, é possível utilizar como ingredientes alternativos ou não convencionais o milheto, o sorgo, o farelo de arroz (integral e desengordurado), os óleos vegetais e as gorduras de origem animal, entre outros.

Atualmente, as pesquisas são realizadas, em sua maioria, com frangos de corte e galinhas poedeiras, sendo necessário que trabalhos sejam desenvolvidos com codornas para determinação do valor nutritivo de alimentos, no intuito de permitir a correta formulação de rações para esta espécie, maximizando principalmente a produtividade.

Objetivou-se neste estudo determinar os valores de energia metabolizável aparente e verdadeira (EMA e EMV) corrigidos pelo balanço de nitrogênio (EMAn e EMVn), e o coeficiente de metabolização da energia bruta (CMEB) de 12 alimentos protéicos e energéticos para codornas japonesas.

\section{Material e Métodos}

O experimento foi conduzido no setor de coturnicultura da Universidade José do Rosário Vellano - UNIFENAS, Alfenas - MG.

Foram utilizadas 250 codornas em postura, distribuídas em quatro ensaios distintos, sendo utilizadas 50 aves para cada alimento testado. O número de alimentos testados em cada ensaio foi variável. As gaiolas metálicas (32 x $38 \times 16 \mathrm{~cm})$ foram equipadas com comedouros tipo calha, bebedouros tipo nipple e bandejas para coleta das excretas e distribuídas em cinco andares, cada um com cinco gaiolas, em uma densidade de 10 aves/gaiola. No período do experimento, as aves foram mantidas sob um programa de luz de 16,5 horas/dia (natural + artificial).

Quando as aves completaram 19 semanas de idade, deu-se início ao período experimental, no qual foram realizados quatro ensaios seqüenciais com seus respectivos tratamentos (cada um com cinco repetições). Os ensaios foram realizados em intervalos de sete dias e tiveram oito dias de duração - cinco para adaptação às rações e três para coleta das excretas. Foram avaliados, nos quatro ensaios, dois grupos de alimentos: protéicos (farinha de carne e ossos $(45 \%)$, farinha de peixe $(54 \%)$, farinha de penas e vísceras e duas marcas comerciais de farelos de soja - 1 e 2), incorporados a uma ração-referência (Tabela 1) formulada segundo recomendações do NRC (1994), com base na matéria natural, nas proporções de 20 e $30 \%$ para os de origem animal e vegetal, respectivamente; e energéticos (milheto, sorgo, farelo de arroz integral, óleo de soja refinado, gordura de aves, sebo bovino e gordura de suínos), também incorporados a uma ração-referência, na matéria natural, nas proporções de 40 (para os de origem vegetal) e $10 \%$ (parao óleo eas gorduras), totalizando 12 alimentos.

A composição química e energética dos alimentos es tudados encontra-se na Tabela 2.

Adotou-se o método de coleta total de excretas, utilizando-se o óxido férrico como marcador fecal para identificar o início e o final do período de coleta em cada ensaio. Durante o período de adaptação, o fornecimento de ração foi à vontade, em duas vezes ao dia, na proporção de 25 g/ave/dia. Entretanto, durante o período de coleta, 
mesmo com o fornecimento à vontade, procedeu-se ao arraçoamento três vezes ao dia, de forma controlada, para evitar o desperdício. No final do período de coleta, em cada ensaio, todas as sobras de cada tratamento foram reunidas e pesadas para determinação do consumo.

As excretas foram coletadas em bandejas metálicas devidamente forradas com lonas plásticas, uma vez ao dia (16h), tomando-se o cuidado de se proceder à criteriosa limpeza das excretas, retirando penas e grânulos de ração. Após as coletas, as excretas foram pesadas, acondicionadas em sacos plásticos identificados de acordo com sua parcela e armazenadas em freezer $\left(-5^{\circ} \mathrm{C}\right)$ até o período final de coleta em cada ensaio, quando as excretas foram descongeladas, devidamente homogeneizadas e pesadas, retirando-se $450 \mathrm{~g}$ de amostra por parcela. As amostras foram secas em estufa de ventilação forçada por 72 horas a $55^{\circ} \mathrm{C}$. Após a pré-secagem, foram moídas e acondicionadas em potes plásticos para posteriores análises.

Simultaneamente, um grupo de 30 aves foi separado e alojado em cinco repetições de 6 aves/gaiola para determinação das perdas endógenas. As aves foram mantidas em jejum por 48 horas e todo o material excretado foi coletado a partir da 4 a hora e submetido ao mesmo processo descrito para as parcelas que receberam os tratamentos, realizando-se, ao final do experimento, a correção das perdas endógenas para os três dias de coleta.

As rações-referência e os 12 alimentos testados foram encaminhados ao laboratório para análise bromatológica e determinação da energia bruta em bomba calorimétrica adiabática modelo PARR. Foram determinados os teores de MS e a energia bruta das excretas coletadas, sendo todas as análises realizadas segundo metodologias descritas por Silva (1990).
Ao final dos ensaios, com base nos resultados laboratoriais, foram determinados os valores de energia metabolizável aparente (EMA), utilizando-se as equações descritas por Matterson et al. (1965), e realizados os ajustes para retenção de nitrogênio para determinação da energia metabolizável aparente corrigida (EMAn). Foram realizadas ainda algumas adaptações nestas equações para determinação

Tabela 1 - Composição percentual da ração-referência Table 1 - Ingredient and nutrient compositions of the reference diet

Ingrediente $\%$

Ingredient

Milho (Corn) 57,340

Farelo de soja (Soybean meal)

32,944

Fosfato bicálcico (Dicalcium phosphate) $\quad 1,306$

Calcário calcítico (Limestone) $\quad 5,348$

Óleo de soja (Soybean oil) $\quad 2,431$

Sal comum (Salt) $\quad 0,291$

Premix mineral ${ }^{1}$ (Mineral premix) 0,100

Premix vitamínico ${ }^{2}$ (Vitamin premix) $\quad 0,100$

DL-metionina (99\%) (DL-methionine 99\%) 0,140

Composição calculada

Calculated composition

$\mathrm{EM}(\mathrm{kcal} / \mathrm{kg})(M E, k c a l / k g) \quad 2900$

$\mathrm{PB}, \%(C P, \%) \quad 20$

$\mathrm{Ca}, \% \quad 2,5$

P disponível, \% (Available $P, \%$ ) $\quad 0,35$

$\mathrm{Na}, \% \quad 0,15$

Lisina, \% (Lysine, \%) $\quad 1,00$

Metionina, \% (Methionine, \%) $\quad 0,45$

Metionina + Cistina, \% (Methionine + Cystine, \%) $\quad 0,70$

1 Suplementação por kg de ração (Supplementation per kg of diet): $\mathrm{Mn}-70$ ppm; $\mathrm{Zn}-60$ ppm; $\mathrm{Fe}-50$ ppm; $\mathrm{Cu}-8,5$ ppm; I 1 ppm; Co - 0,2 ppm.

2 Suplementação por $\mathrm{kg}$ de ração (Supplementation per $\mathrm{kg}$ of diet): vit. A $7.000 \mathrm{UI}$; vit. $\mathrm{D}_{3}-2.100 \mathrm{UI}$; vit. $\mathrm{E}-50 \mathrm{UI}$; vit. $\mathrm{K}_{3}-2,0 \mathrm{mg}$; vit. $\mathrm{B}_{1}$ $2,0 \mathrm{mg}$; vit. $\mathrm{B}_{2}-4,0 \mathrm{mg}$; niacina (niacin) - $39,8 \mathrm{mg}$; ácido pantotênico (pantothenic acid) - 15,6; vit. $B_{6}-3,0 \mathrm{mg}$; vit. $B_{12}-0,030 \mathrm{mg}$; ácido fólico (folic acid) - 1,0 mg; biotina (biotin) - 0,10 mg; Se - 0,20 mg.

Tabela 2 - Composições química e energética dos alimentos, na matéria natural ${ }^{1}$

Table 2 - Chemical and energy compositions of feedstuffs, as-fed basis

\begin{tabular}{|c|c|c|c|c|c|c|}
\hline $\begin{array}{l}\text { Alimento } \\
\text { Feedstuff }\end{array}$ & $\begin{array}{c}\mathrm{MS}(\%) \\
D M\end{array}$ & $\begin{array}{c}\text { Cinzas (\%) } \\
\text { Ash }\end{array}$ & $\begin{array}{c}\mathrm{PB}(\%) \\
C P\end{array}$ & $\begin{array}{c}\mathrm{EE}(\%) \\
E E\end{array}$ & $\begin{array}{c}\mathrm{FB}(\%) \\
\quad C F\end{array}$ & $\begin{array}{c}\mathrm{EB}(\mathrm{kcal} / \mathrm{kg})^{2} \\
G E\end{array}$ \\
\hline Farinha de carne e ossos(Meat and bone meal) & 93,16 & 31,89 & 45,73 & 14,08 & - & 3.363 \\
\hline Farinha de penas e vísceras (Viscera and feathers meal) & 88,87 & 5,22 & 63,76 & 13,63 & - & 5.191 \\
\hline Farelo de soja 1 (Soybean meal 1) & 87,96 & 5,17 & 46,73 & 1,97 & 4,98 & 4.155 \\
\hline Farelo de soja 2 (Soybean meal 2) & 87,51 & 4,97 & 46,87 & 2,03 & 5,22 & 4.162 \\
\hline Farelo de arroz integral (Whole rice bran) & 89,26 & 8,69 & 12,16 & 12,59 & 9,41 & 3.585 \\
\hline Óleo de soja refinado (Refined soybean oil) & 99,43 & - & - & 99,43 & - & 9.000 \\
\hline Gordura de aves (Poultry fat) & 99,31 & - & - & 98,48 & - & 9.188 \\
\hline Sebo bovino (Beeftallow) & 99,17 & - & - & 99,17 & - & 9.061 \\
\hline Gordura de suínos (Swine fat) & 99,38 & - & - & 99,38 & - & 9.110 \\
\hline
\end{tabular}

1 Análises realizadas no Laboratório de Análises de Alimentos da Universidade José do Rosário Vellano - UNIFENAS (Analyses were done at the Feedstuffs Analyses Laboratory at José do Rosário Vellano University - UNIFENAS).

${ }^{2}$ Análise realizada no Laboratório de Pesquisa Animal da Universidade Federal de Lavras - UFLA (Analysis was done at the Animal Research Laboratory at Federal University of Lavras - UFLA). 
da energia metabolizável verdadeira (EMV) e verdadeira corrigida pelo balanço de nitrogênio (EMVn).

O coeficiente de metabolização da energia bruta (CMEB) foi obtido pela porcentagem de EB convertida em EMA (ARC, 1980). Os valores do coeficiente de metabolização da EB foram submetidos à análise de comparação múltipla pelo teste Tukey, por meio do Sistema para Análises de Variância - SISVAR, segundo Ferreira (2000).

Fórmulas utilizadas no cálculo da EM e no coeficiente de metabolização da EB:

$\mathrm{EMA}_{(\mathrm{RT})}$ ou $\mathrm{EMA}_{(\mathrm{RR})}=(\mathrm{EB}$ ingerida $-\mathrm{EB}$ excretada $) / \mathrm{MS}$ ingerida

EMA do alimento $=\mathrm{EMA}_{(\mathrm{RR})}+\left(\mathrm{EMA}_{(\mathrm{RT})}-\mathrm{EMA}_{(\mathrm{RR})}\right) / \mathrm{g} /$ g de substituição

$\operatorname{EMAn}_{(\mathrm{RT})}$ ou $\mathrm{EMAn}_{(\mathrm{RR})}=\mathrm{EB}$ ingerida $-(\mathrm{EB}$ excretada + $8,22 \times \mathrm{BN}$ ) / MS ingerida

$\mathrm{BN}=(\mathrm{N}$ ingerido $-\mathrm{N}$ excretado $)$

$\mathrm{EMV}_{(\mathrm{RT})}$ ou $\mathrm{EMV}_{(\mathrm{RR})}=\mathrm{EB}$ ingerida $-(\mathrm{EB}$ excretada $-\mathrm{EB}$ endógeno) / MS ingerida

$\mathrm{EMVn}_{(\mathrm{RT})}$ ou EMVn $(\mathrm{RR})=\mathrm{EB}$ ingerida $-(\mathrm{EB}$ excretada $-\mathrm{EB}$ endógeno $+8,22 \times \mathrm{BNV}) / \mathrm{MS}$ ingerida

$\mathrm{BNV}=(\mathrm{N}$ ingerido $-(\mathrm{N}$ excretado $-\mathrm{N}$ endógeno $))$

$\mathrm{CMEB}=\mathrm{EMA} / \mathrm{EB}$ do alimento $\mathrm{x} 100$

em que: $\mathrm{EB}=$ energia bruta; $\mathrm{MS}$ = matéria seca; $\mathrm{BN}=$ balanço de nitrogênio; $\mathrm{BNV}=$ balanço de nitrogênio verdadeiro; $\mathrm{RT}=$ ração com alimento-teste; e RR = ração-referência.

Cada ensaio foi realizado em um delineamento em blocos casualizados, sendo o bloco representado pelos diferentes andares das gaiolas.

Os resultados dos valores energéticos obtidos foram apresentados juntamente com seus desvios-padrão e, para efeitos comparativos, foram descritos com base no teor de MS.

\section{Resultados e Discussão}

Os valores de energia dos diferentes alimentos protéicos estudados são apresentados na Tabela 3. Os valores de EMA em todos os alimentos estudados foram, em média, $5 \%$ inferiores aos de EMAn, reflexo da retenção negativa de nitrogênio observada no experimento, comportamento que contradiz o observado por Rodrigues et al. (2002), que, em estudo com pintos alimentados à vontade, observaram maior valor para a EMA que para a EMAn, considerando-se retenção de nitrogênio positiva (maior que zero), ou seja, quando as aves estavam em crescimento. Resultados semelhantes foram observados por Albino et al. (1992), que, no entanto, trabalhando com galos adultos e utilizando o método de ingestão forçada, observaram valores de EMA menores que os de EMAn, o que se assemelha aos resultados encontrados nesta pesquisa.

Entre os alimentos protéicos de origem animal estudados, a farinha de penas e vísceras apresentou os maiores valores de EMA e EMAn, porém, com EMAn inferior ao determinado por Rostagno et al. (2005) para aves, de $3.566 \mathrm{kcal} / \mathrm{kg}$ de MS, variação parcialmente explicada pela composição da farinha utilizada, que apresentou menores teores de MS, PB e EE em relação à composição da farinha de penas e vísceras apresentada nas tabelas brasileiras para aves e suínos.

A farinha de carne e ossos apresentou os menores valores de EMA e EMAn em relação aos demais alimentos avaliados. No entanto, os valores energéticos desse alimento foram superiores aos determinados por Albino et al. (1992), de 2.660 e $2.420 \mathrm{kcal} / \mathrm{kg}$ de MS, e Soares et al. (2005), de 2.431 e $2.065 \mathrm{kcal} / \mathrm{kg}$ de MS, e à EMAn determinada por Nunes et al. (2005), de $2.496 \mathrm{kcal} / \mathrm{kg}$ de MS, observando-se que todos esses autores trabalharam com pintos em crescimento.

Os valores de EMA e EMAn obtidos para a farinha de peixe para codornas em postura $(2.858$ e $3.035 \mathrm{kcal} / \mathrm{kg}$ de MS, respectivamente) foram menores que o de EMA obtido por Silva et al. (2003), para codornas mistas em crescimento (3080 kcal/kg de MS). Esta variação possivelmente esteve relacionada à retenção de nitrogênio positiva observada por esse autor. Os resultados de EMA e EMAn da farinha de peixe foram superiores aos apresentados por Murakami $\&$ Furlan (2002), em codornas aos 65 dias de idade (2.662 e $2.480 \mathrm{kcal} / \mathrm{kg}$ de MS, respectivamente).

Entre os alimentos protéicos de origem vegetal, os farelos de soja 1 e 2 apresentaram valores de EMAn superiores aos determinados por Furlan et al. (1998), em codornas com 65 dias de idade $(2.980 \mathrm{kcal} / \mathrm{kg}$ de MS), e aos obtidos por Silva et al. (2003), em codornas mistas em crescimento $(2.797 \mathrm{kcal} / \mathrm{kg}$ de MS).

Comparando os valores de energia metabolizável aparente corrigida (EMAn) obtidos neste experimento aos valores determinados com frangos de corte ou galinhas poedeiras, relatados por Rostagno et al. (2005), verificou-se superioridade de $26,85 \%$ para o farelo de soja 2 (3.231 vs $2.546 \mathrm{kcal} / \mathrm{kg}$ de MS), de 23,63\% para o farelo de soja 1 (3.149 vs $2.546 \mathrm{kcal} / \mathrm{kg}$ de MS), de $6,6 \%$ para a farinha de peixe 
Tabela 3 - Valores energéticos dos alimentos protéicos, com base na MS Table 3 - Energy values of protein feedstuffs on DM basis

\begin{tabular}{|c|c|c|c|c|c|}
\hline Alimento & EMA $(\mathrm{kcal} / \mathrm{kg})$ & $\operatorname{EMAn}(\mathrm{kcal} / \mathrm{kg})$ & $\operatorname{EMV}(\mathrm{kcal} / \mathrm{kg})$ & $\operatorname{EMVn}(\mathrm{kcal} / \mathrm{kg})$ & $\mathrm{CMEB}^{1,2}(\%)$ \\
\hline Feedstuff & $A M E$ & $A M E$ & $T M E$ & TMEn & $M G E C$ \\
\hline Far. carne e ossos (Meat and bone meal) & $2.673(46)$ & $2.796(46)$ & $2.930(48)$ & $2.814(47)$ & $74,06(1,4)^{\mathrm{a}}$ \\
\hline Far. penas e vísceras (Viscera and feathers meal) & $3.285(104)$ & $3.461(87)$ & $3.579(71)$ & $3.476(76)$ & $56,24(2)^{\mathrm{c}}$ \\
\hline Farelo de soja 1 (Soybean meal 1) & $2.974(48)$ & $3.149(55)$ & $3.227(52)$ & $3.180(54)$ & $62,9(1,1)^{\mathrm{b}}$ \\
\hline Farelo de soja 2 (Soybean meal 2) & $3.095(81)$ & $3.231(76)$ & $3.334(28)$ & $3.272(30)$ & $65,1(1,9)^{b}$ \\
\hline $\mathrm{CV}(\%)$ & & & & & 2,61 \\
\hline
\end{tabular}

${ }^{1}$ Médias seguidas por letras distintas na coluna são diferentes $(\mathrm{P}<0,01)$ pelo teste Tukey (Means followed by different letters in the column differ [P<0.01] by Tukey test). ${ }^{2}$ Porcentagem de EB convertida em EMA (Percentage of GE converted to AME).

(3.035 vs $2.847 \mathrm{kcal} / \mathrm{kg}$ de MS) e de $6,27 \%$ para a farinha de carne e ossos (2.796 vs $2.632 \mathrm{kcal} / \mathrm{kg}$ de MS), ressaltando-se que somente a farinha de penas e vísceras apresentou valor $2,94 \%$ inferior (3.461 vs $3.566 \mathrm{kcal} / \mathrm{kg}$ de MS).

A farinha de carne e ossos apresentou o maior (74,06\%) e a farinha de penas e vísceras, o menor $(56,24 \%)$ coeficiente de metabolização da EB (CMEB). Para a farinha de peixe, obteve-se CMEB de 63,89\%, superior ao determinado por Silva et al. (2003). Para os farelos de soja estudados, estimou-se valor médio de $63,98 \%$, semelhante ao encontrado por Furlan et al. (1998), de 63,29\%, e superior ao descrito por Silva et al. (2003), de 50,12\%.

Quanto à EMV, todos os alimentos protéicos estudados apresentaram valores, em média, 2,73\% superiores aos de EMVn e 8,79\% superiores aos de EMA.Segundo Leclercq et al. (1999), a EMV é 5 a 10\% superior à EMA, sendo influenciada basicamente pelos valores de consumo, que, por sua vez, dependem do método utilizado na determinação dos valores energéticos.

Entre os alimentos protéicos de origem animal, a farinha de penas e vísceras apresentou também os maiores valores de EMV e EMVn (3.579 e $3.476 \mathrm{kcal} / \mathrm{kg})$; no entanto, o valor de EMVn foi inferior ao referenciado por Rostagno et al. (2005), de $3.804 \mathrm{kcal} / \mathrm{kg}$. A farinha de carne e ossos, por sua vez, apresentou os menores valores de EMV e EMVn, que foram, no entanto, superiores aos determinados por Soares et al. (2005) em pintos em crescimento $(2.526 \mathrm{e}$ $2.129 \mathrm{kcal} / \mathrm{kg}$ de MS). A farinha de peixe apresentou valores intermediários de EMV e EMVn(3.249 e $3.133 \mathrm{kcal} / \mathrm{kg}$, respectivamente), superiores aos obtidos por Albino et al. (1992), de 3.110 e $2.890 \mathrm{kcal} / \mathrm{kg}$ de MS. O mesmo foi observado para os valores médios encontrados para os farelos de soja 1 e 2 (3.280 vs 2.750 e 3.226 vs $2.540 \mathrm{kcal} / \mathrm{kg}$ de MS), determinados pelo método tradicional de coleta total de excretas.

Os farelos de soja apresentaram valores de EB semelhantes, o que não foi observado para EMAn e EMVn. As diferenças podem ser atribuídas às variações no diâmetro geométrico médio (DGM) das partículas e à porcentagem de casca adicionada a cada farelo de soja, características não avaliadas neste trabalho.

Comparando-se os valores de EMVn obtidos neste experimento aos referenciados por Rostagno et al. (2005), observou-se superioridade de $16,6 \%$ para o farelo de soja 2 (3.272 vs $2.806 \mathrm{kcal} / \mathrm{kg}$ de MS) e de $13,32 \%$ para o farelo de soja 1 ( 3.180 vs $2.806 \mathrm{kcal} / \mathrm{kg}$ de MS). Verificou-se ainda um valor inferior, de $8,62 \%$, para a farinha de penas e vísceras (3.476 vs $3.804 \mathrm{kcal} / \mathrm{kg}$ de MS) e de 5,68\% para a farinha de peixe ( $3.133 \mathrm{vs} 3.322 \mathrm{kcal} / \mathrm{kg}$ de MS). Os valores obtidos para a farinha de carne e ossos (45\%) não puderam ser comparados, pois os valores de EMVn deste alimento não foram descritos por Rostagno et al. (2005).

Outro aspecto importante a ser estudado é o uso de alimentos de origem animal em rações para aves, visto que estes alimentos, na sua maioria, apresentam pouca padronização em suas composições, em virtude do processamento a que são submetidos e ao tipo e às proporções de seus constituintes. Segundo Albino \& Silva(1996), essa ausência de padronização decorre da dificuldade dos setores de graxaria dos abatedouros em estabelecer um padrão contínuo nos ingredientes utilizados.

Os valores de energia metabolizável e o coeficiente de metabolização da EB (CMEB) dos alimentos energéticos estudados são apresentados na Tabela 4.

Os valores de EMA dos alimentos energéticos estudados foram, em média, 2,52\% inferiores aos de EMAn e os de EMV, em média, 1,58\% superiores aos de EMVn e 6,44\% superiores aos de EMA.

Entre os alimentos energéticos de origem vegetal estudados, o sorgo apresentou os maiores valores de EMA e EMAn (3.811 e $3.943 \mathrm{kcal} / \mathrm{kg}$ de MS, respectivamente), com valor de EMAn superior ao encontrado por Rostagno et al. (2005) em experimento com aves (3.628 kcal/kg de MS), variação parcialmente explicada pela composição do sorgo utilizado, que apresentou menores teores de FB e maiores teores de PB e EE em relação ao utilizado por Rostagno et al. (2005). 
Tabela 4 - Valores de energia dos alimentos energéticos, com base na MS Table 4 - Energy values of energy feedstuffs on DM basis

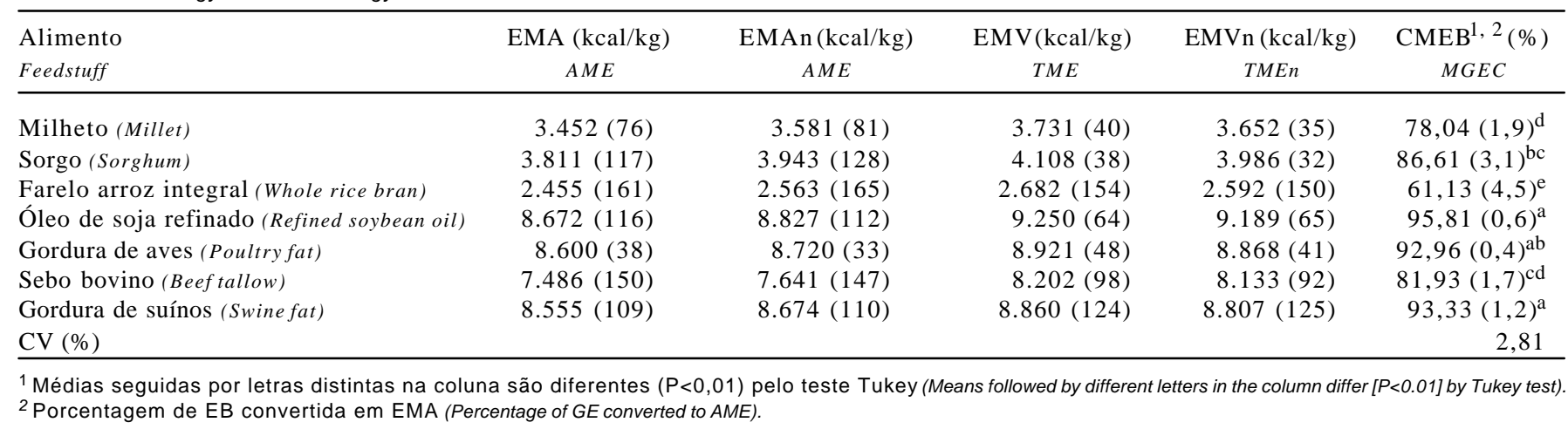

Os menores valores de EMA e EMAn foram obtidos no farelo de arroz integral (2.455 e $2.563 \mathrm{kcal} / \mathrm{kg}$ de MS), cujos valores foram inferiores também aos determinados por Furlan et al. (1998), com codornas machos aos 65 dias de idade (3.458 e $3.473 \mathrm{kcal} / \mathrm{kg}$ de MS), e Albino et al. (1992), em experimento com pintos em crescimento pelo método tradicional de coleta total de excretas $(3.330$ e $3.200 \mathrm{kcal} / \mathrm{kg}$ de MS). Os valores de EMA e EMAn obtidos para o milheto com codornas em postura foram intermediários (3.452 e $3.581 \mathrm{kcal} / \mathrm{kg}$, respectivamente), porém superiores aos de terminados por Rodrigues et al. (2001) com galos adultos e pintos em crescimento $(3.152$ e $3.487 ; 3.361$ e $3.297 \mathrm{kcal} / \mathrm{kg}$ de MS, respectivamente).

Os valores de EMA e EMAn obtidos para o óleo de soja refinado, o sebo bovino, a gordura de suínos e a gordura de aves foram superiores aos determinados por Nascif et al. (2004), trabalhando com pintos de corte mistos (8.672 e 8.827 vs 8.394 e $8.389 ; 7.486$ e 7.641 vs 7.333 e $7.329 ; 8.555$ e 8.674 vs 7.624 e $7.619 ; 8.600$ e 8.720 vs 8.587 e $8.579 \mathrm{kcal} / \mathrm{kg}$ de MS, respectivamente)

Comparando os valores de EMAn obtidos neste experimento aos determinados para frangos de corte ou galinhas poedeiras por Rostagno et al. (2005), verificou-se superioridade de $8,68 \%$ para sorgo (3.943 vs $3.628 \mathrm{kcal} / \mathrm{kg}$ de MS), de $6,87 \%$ para a gordura de suínos (8.674 vs $8.116 \mathrm{kcal} / \mathrm{kg}$ de MS) e de $2,61 \%$ para o sebo bovino (7.641 vs $7.446 \mathrm{kcal} / \mathrm{kg} \mathrm{de} \mathrm{MS}$ ), sendo semelhantes aos resultados encontrados para o milheto, para a gordura de aves e para o óleo de soja refinado, com diferença de apenas 1,32\% (3.581 vs $3.534 \mathrm{kcal} / \mathrm{kg}$ de MS), $0,05 \%$ ( $8.720 \mathrm{vs} 8.715 \mathrm{kcal} / \mathrm{kg}$ de MS) e $0,02 \%$ ( $8.827 \mathrm{vs}$ $8.825)$, respectivamente. Somente o farelo de arroz integral apresentou valor de EMAn 9,65\% inferior (2563 vs $2837 \mathrm{kcal} /$ $\mathrm{kg}$ de MS) aos descritos por Rostagno et al. (2005).

O óleo de soja refinado e a gordura de suínos apresentaram os maiores coeficientes de metabolização da energia bruta (CMEB), 95,81 e 93,32\%, respectivamente, sendo seguidos pela gordura de aves $(92,96 \%)$, pelo sorgo
$(86,61 \%)$, pelo sebo bovino $(81,93 \%)$ e pelo milheto $(78,04 \%)$, enquanto o farelo de arroz integral apresentou o menor coeficiente $(61,13 \%)$, justificado principalmente pelo alto teor de FB, decorrentes da dificuldade de padronização desse alimento.

Nos mesmos alimentos energéticos de origem vegetal, o sorgo apresentou os maiores valores de EMV e EMVn (4.108 e $3.986 \mathrm{kcal} / \mathrm{kg})$. Os valores de EMVn mantiveram-se, portanto, um pouco acima dos referenciados por Rostagno et al. (2005), de $3.957 \mathrm{kcal} / \mathrm{kg}$ de MS. O farelo de arroz integral, por sua vez, apresentou valores de EMV e EMVn menores $(2.682$ e $2.592 \mathrm{kcal} / \mathrm{kg}$ ) que os determinados por Albino et al. (1992), com pintos em crescimento, de 3.430 e $3.270 \mathrm{kcal} / \mathrm{kg}$ de MS. O milheto apresentou valores intermediários de EMV e EMVn (3.731 e $3.652 \mathrm{kcal} / \mathrm{kg}$ de MS, respectivamente), inferiores, porém, aos obtidos por Rodrigues et al. (2001) com galos adultos $(3.968$ e $3.761 \mathrm{kcal} / \mathrm{kg}$ de MS) e superiores aos determinados com pintos em crescimento (3.438 e $3.357 \mathrm{kcal} / \mathrm{kg}$ de $\mathrm{MS}$ ).

Entre os valores de EMVn dos alimentos estudados e aqueles referenciados por Rostagno et al. (2005), observou-se uma diferença inferior, de $26 \%$, para o farelo de arroz integral (2.592 vs $3.519 \mathrm{kcal} / \mathrm{kg}$ de MS), de 3,55\% para a gordura de aves ( 8.868 vs $9.195 \mathrm{kcal} / \mathrm{kg}$ de MS) e de $2,37 \%$ para o milheto (3.652 vs $3.741 \mathrm{kcal} / \mathrm{kg}$ de MS). Para o óleo de soja refinado e o sebo bovino, no entanto, apesar de seus valores inferiores, as diferenças foram pequenas, de $0,5 \%$ (9.189 vs $9.236 \mathrm{kcal} / \mathrm{kg} \mathrm{MS})$ e de $0,39 \%$ ( $8.133 \mathrm{vs}$ $8.165 \mathrm{kcal} / \mathrm{kg}$ de MS), respectivamente, e o sorgo, apesar de uma ligeira diferença (de $0,73 \%$ ), foi o único alimento com valor superior (3.986 vs $3.957 \mathrm{kcal} / \mathrm{kg}$ de MS). A gordura de suínos não pôde ser comparada, pois, nas tabelas de Rostagno et al. (2005), não constam os valores de EMVn deste alimento.

Observou-se, em todos os valores energéticos do experimento, uma nítida superioridade da EMAn em relação à EMA. O mesmo foi observado por Rodrigues et al. (2002), 
entre os valores de EMV em relação à EMVn, em galos adultos. Similarmente, os valores de EMVn foram superiores aos de EMAn, evidenciando os efeitos das energias fecal metabólica e urinária endógena sobre os valores de EM.

As diferenças entre os valores de EMAn e EMVn deste experimento e os descritos por Rostagno et al. (2005) podem ser atribuídas a possíveis diferenças entre as composições bromatológicas dos ingredientes utilizados nas rações para aves (principalmente por se tratar de alimentos alternativos) e, por isso, essas comparações seriam melhor visualizadas em valores expressos na MS. De acordo com Bellaver et al. (2005), em toda consideração acerca de alimentos convencionais, alternativos ou subprodutos, deve-se defender basicamente a melhoria de sua qualidade, considerando-os sempre como ingredientes, e não como commodities.

Outras variações observadas no experimento, especialmente quando se comparam resultados obtidos entre espécies diferentes de aves ou aves com idades não semelhantes, são explicadas, entre outros fatores individuais, pela maior velocidade de passagem do alimento pelo trato digestório da codorna. No entanto, mesmo sabendo da maior velocidade de passagem, pouco se conhece das relações entre o aproveitamento do alimento e a idade das aves.

É importante ressaltar que o uso de gorduras de origem animal em dietas para aves consiste em alternativa econômica tanto para a indústria como para os criadores, pois este tipo de alimento tem custo menor em relação aos óleos vegetais.

\section{Conclusões}

Os valores energéticos dos alimentos estudados neste experimento, determinados com codornas, diferiram dos determinados com frangos de corte e galinhas poedeiras, fato que deve ser considerado na formulação de rações.

\section{Literatura Citada}

AGRICULTURAL RESEARCH COUNCIL - ARC.The nutritional requirement of ruminant livestock. London: $C A B$ International, 1980. 351p.

ALBINO, L.F.T.; ROSTAGNO, H.S.; TAFURI, M.L. et al. Determinação dos valores de energia metabolizável aparente e verdadeira de alguns alimentos para aves, usando diferentes métodos. Revista da Sociedade Brasileira de Zootecnia, v.21, n.6, p.1047-1058, 1992.

ALBINO, L.T.F.; SILVA, M.A. Valores nutritivos de alimentos para aves e suínos determinados no Brasil. In: SIMPÓSIO INTERNACIONAL SOBRE EXIGÊNCIAS NUTRICIONAIS DE AVES E SUÍNOS, 1996, Viçosa, MG. Anais... Viçosa, MG: Universidade Federal de Viçosa, 1996. p.303-318.

ANNISON, G.; CHOCT, M. Anti-nutritive activities of cereal nonstarch polysaccharides in broiler diets and strategies minimizing their effects. World Poultry Science Journal, v.47, p.222$241,1991$.

BELLAVER, C.; LUDKE, J.; LIMA, G.J.M.M. Qualidade de ingredientes para rações. In: GLOBAL FEED AND FOOD FORUM, 2005, São Paulo. Anais... São Paulo: 2005. p.192-216.

FERREIRA, D.F. SISVAR - Sistema para análise de variância. Lavras: Universidade Federal de Lavras (Departamento de Ciências Exatas - DEX), 2000. (CD-ROM).

FIALHO, E.T.; BARBOSA, H.P. Alimentos alternativos para suínos. Lavras: Universidade Federal de Lavras, 1999. 196p.

FURLAN, A.C.; ANDREOTTI, M.O.; MURAKAMI, A.E. et al. Valor energético de alguns alimentos determinados com codornas japonesas (Coturnix coturnix japonica). Revista Brasileira de Zootecnia, v.27, n.6, p.1147-1150, 1998.

LÁZARO, R.; SERRANO, M.P.; CAPDEVILA, J. Nutrición y alimentación de avicultura complementaria: codornices: Madrid: Universidad Politécnica de Madrid, 2005. p.369-408.

LECLERCQ, B.; HENRY, Y.; PEREZ, J.M. Valor energético dos alimentos destinados aos animais monogástricos. In: INSTITUT NATIONAL DE LA RECHERCHE AGRONOMIQUE - INRA (Ed.) Alimentação dos animais monogástricos: suínos, coelhos e aves. 2.ed. São Paulo: Roca, 1999. p.9-15.

MATTERSON, L.D.; POTTER, L.M.; STUTZ, N.W. The metabolizable energy of feeds ingredients for chickens. Storrs: University of Connecticut - Agricultural Experiment Station, 1965. 11p. (Research Report, 7).

MURAKAMI, A.E.; FURLAN, A.C. Pesquisa na nutrição e alimentação de codornas em postura no Brasil. In: SIMPÓSIO INTERNACIONAL DE COTURNICULTURA, 2002, Lavras. Anais... Lavras: Universidade Federal de Lavras, 2002. p. $113-120$

NASCIF, C.C.C.; GOMES, P.C.; ALBINO, L.F.T. et al. Determinação dos valores energéticos de alguns óleos e gorduras para pintos de corte machos e fêmeas aos 21 dias de idade. Revista Brasileira de Zootecnia, v.33, n.2, p.375-385, 2004.

NATIONAL RESEARCH COUNCIL - NRC. Nutrient requirements of poultry. 9.ed. Washington: National Academy Press, 1994. $155 \mathrm{p}$.

NUNES, R.V.; POZZA, P.C.; NUNES, C.G.V. et al. Valores energéticos de subprodutos de origem animal para aves. Revista Brasileira de Zootecnia, v.34, n.4, p.1217-1224, 2005.

RODRIGUES, P.B.; ROSTAGNO, H.S.; ALBINO, L.F.T. et al. Valores energéticos do milheto, do milho e subprodutos do milho, determinados com frangos de corte e galos adultos. Revista Brasileira de Zootecnia, v.30, n.6, p.1767-1778, 2001.

RODRIGUES, P.B.; ROSTAGNO, H.S.; ALBINO, L.F.T. et al. Valores energéticos da soja e subprodutos da soja, determinados com frangos de corte e galos adultos. Revista Brasileira de Zootecnia, v.31, n.4, p.1771-1782, 2002.

ROSTAGNO, H.S.; ALBINO, L.F.T.; DONZELE, J.L. et al.Tabelas brasileiras para aves e suínos: composição de alimentos e exigências nutricionais. Viçosa, MG: Universidade Federal de Viçosa, 2005. 186p.

SILVA, D.J. Análise de alimentos: métodos químicos e biológicos. 2.ed. Viçosa, MG: Universidade Federal de Viçosa, 1990. 165p

SILVA, J.H.V.; SILVA, M.B.; SILVA, E.L. et al. Energia metabolizável de ingredientes determinados com codornas japonesas (Coturnix coturnix japonica). Revista Brasileira de Zootecnia, v.32, n.6, p.1912-1918, 2003

SOARES, K.R.; BERTECHINI, A.G.; FASSANI, E.J. et al. Valores de energia metabolizável de alimentos para pintos de corte na fase pré-inicial. Ciência e Agrotecnologia, v.29, n.1, p.238244, 2005. 